\title{
Global change, ensuing vulnerabilities, and social responses in marine environments
}

\author{
Alida Bundy ${ }^{1} \cdot$ Ratana Chuenpagdee $^{2} \cdot$ Sarah Cooley $^{3} \cdot$ Bernhard Glaeser $^{4} \cdot$ \\ Liana Talaue McManus ${ }^{5}$
}

Received: 16 November 2015/ Accepted: 22 November 2015/Published online: 6 January 2016

(C) Crown Copyright 2016

Far above the world, Planet Earth is blue, And there's nothing I can doDavid Bowie

Davis Bowie is wrong. But not about our planet being blue. Our planet is habitable because it is blue, and it is blue because it is largely composed of oceans. Our oceans are essential for all life on earth, providing us with the air that we breathe, absorbing the carbon dioxide that we exhale, providing us with food for survival and soothing our human souls via its aesthetic qualities. Globally, we have taken our oceans for granted, being largely ignorant of their many functions that are indispensable to us, and assuming them to be inexhaustible. Yet, they have limits, and contradicting Bowie, there is much that can be done to keep our planet blue and its natural and social components healthy.

Alida Bundy

alida.bundy@dfo-mpo.gc.ca

Ratana Chuenpagdee

ratanac@mun.ca

Sarah Cooley

scooley@oceanconservancy.org

Bernhard Glaeser

bernhardglaeser@gmail.com

Liana Talaue McManus

Liana.McManus@unep.org

1 Fisheries and Oceans Canada, Bedford Institute of Oceanography, PO Box 1006, Dartmouth NS B2Y 4A2, Canada

2 Memorial University, St. John's, Canada

3 Ocean Conservancy, Washington, DC, USA

4 German Society for Human Ecology, Berlin, Germany

5 UNEP - Global Environment Facility Transboundary Waters Assessment Programme, Washington, DC, USA
We can think of oceans as complex systems, composed of physical and biotic components and processes that interact at multiple spatial and temporal scales. From physical oceanography to biogeochemical cycles through food web interactions to human use of the oceans, a complex set of drivers and responses, and interactions are in dynamic interplay. Such complex systems require the expertise of many disciplines that span the natural and social sciences and humanities, e.g., physical oceanographers, biogeochemists, ecologists, sociologists, anthropologists, historians and folklorists.

From intertidal coastal areas to the open seas, oceans have been subject to the impacts of multiple human activities for centuries (e.g., Jackson et al. 2001; Lotze et al. 2006; Harnik et al. 2012) and our planet is under threat from the cumulative impacts of these activities. Overexploitation, climate change, coastal development, war, and global change are major drivers of change. Addressing the impacts of these drivers requires new approaches in sciences, policy and governance. It requires scientists from multiple disciplines to work together collaboratively on specific issues; it requires transdisciplinary research, which includes non-academic participants. Quintessentially, it requires, as is now being more widely recognized (Editorial 2015; Victor 2015), the active engagement of social sciences to question the very nature of how we respond to and make sense of global change (Lövbrand et al. 2015).

There is a lot that can be done for the blue planet: we just have to figure out how. Researchers, community activists, and leaders are starting to do exactly that, as illustrated in this special collection of papers. The IMBER $^{1}$

\footnotetext{
$\overline{1}$ Integrated Marine Biogeochemistry and Ecosystem Research, www.imber.info.
} 
Human Dimensions Working Group hosted a 3-day workshop entitled "Understanding and forecasting humanocean-human interactions, drivers and pressures, with respect to global change" at the IMBER IMBIZO III Conference, "The future of marine biogeochemistry, ecosystems and societies" (January, 2013, Goa, India). The overall objective of the workshop was to link the effects of global change through natural systems and human systems, identifying their interconnections and vulnerabilities, and creating understanding of the possible futures of these interrelated social, ecological and biogeochemical systems in the continental margins and in the open ocean, and then to build on this scientific understanding and explore the best strategies to mitigate or adapt to the change. Participants were invited to present papers and discuss their experiences with respect to the following themes:

1. An analysis of societal changes in response to or anticipation of global change-their historical contexts and relationships with contemporaneous states of marine environment and institutions

2. Identification of vulnerabilities to global change and evaluation of current capacities to address these

3. Identification of key governance and policy thematic foci to empower societies to address marine environmental change.

The eight papers included in this special collection illustrate a variety of ideas, issues, and responses to the impacts of global change and methodological approaches. Their commonality is in reaching across disciplines to address important issues, considerations of governance, and linked human and social systems. Five papers are strongly rooted in an applied contextual situation, and three papers advance methodological and theoretical approaches.

All three of these themes are addressed by Isaacs (2016) in her paper "Multi-stakeholder process of codesigning small-scale fisheries policy in South Africa," which describes the development of a new small-scale fisheries policy and transformation in South Africa. Key to the success was a transdisciplinary approach described as "research that transcends and integrates disciplinary paradigms in order to address socially (as opposed to academically) relevant issues. The rationale for transcending and integrating disciplinary paradigms is that academic knowledge, organized from a disciplinary perspective, has to be reorganized and re-assessed in order to be relevant for addressing socially relevant issues" (Pohl 2011: 519, cited in Isaacs 2016). It explicitly involves both academia and social actors. Isaacs describes the social and political context in which this transformation occurred, the various necessary steps to finally have the new small-scale fisheries policy adopted by the South African government. The new policy promotes a human rights-based approach, food security, co-management, and customary practices, and allocates multi-species (basket of rights) to community legal entities with a strong development agenda. The role of fisheries stakeholders in driving the process of transformation serves as an excellent example of a bottom-up approach to effect change.

In South Africa, the opportunity for transformation resulted from the ending of apartheid, a systematic war of discrimination by one group of humans on another. War is a human-induced hazard and an ongoing driver of global change, although not one commonly addressed with respect to the oceans or in relation to its impact on fishing communities. However, Munas and Lokuge (2016), addressing themes 1 and 2, explored the impact of three decades of civil war in Sri Lanka on fishing communities in the north and east of the country (Shocks and coping strategies of coastal communities in war-conflict-affected areas of the north and east of Sri Lanka). They conducted a quantitative survey of households in three war-affected coastal districts to explore coping strategies by fishing and non-fishing households using a resilience framework. They hypothesized that coping strategies would be influenced by education level, the extent of livelihood diversification, asset ownership, and ability to borrow. They developed a "Severity index" to measure severity levels of the coping strategies and found differences in the strategies of fishing and non-fishing households, with implications for the development of policy.

On the island of Hawaii, Kittinger et al. (2016) in their paper "Restoring ecosystems, restoring community: socioeconomic and cultural dimensions of a communitybased coral reef restoration project" also addressed themes 1 and 2. Due to the extensive damage to coral reefs from human-induced pressures such as fishing, pollution, and climate change, there has been extensive research into reef restoration, most of which has focused on the ecological benefits or restoration such as restoring habitat quality and reef fish species. However, Kittinger et al. (2016) explored the social dimensions of a large-scale coral reef restoration project, focused on invasive algae removal. They interviewed a wide range of community stakeholders using semi-structured face-to-face methods to assess the socioeconomic and cultural dimensions of the restoration project. Their detailed study revealed many benefits from the project that extended beyond the restoration of the reef, including direct economic benefits such as job creation, revitalization of Hawaiian cultural practices and traditions, and the use of the harvested algae by farmers. Further, community awareness of the reef and general marine environment was raised. Thus, in this case, the communities' capacity to deal with global change (loss of reef) was enhanced by the restoration project. 
The concept of regime shifts, i.e., "an abrupt shift to a dramatically different regime" (Scheffer et al. 2001) has been developed in a natural ecosystems context. Angel et al. (2016) in "Local perspectives on regional challenges: jellyfish proliferation and fish stock management along the Israeli Mediterranean coast" addressed theme 3. They explored policy options in response to an ecological regime shift, thought to be initiated by over-fished demersal fish stocks, pollution, and hypoxia, which have resulted in the proliferation of non-indigenous jellyfish along the Israeli coast. The authors paid specific attention to combining fishing and conservation policies to increase the policies' acceptability among key stakeholders. The authors propose management measures to increase the abundance of demersal fish stocks, with the goal of increasing their ability to compete with jellyfish. The management measures they proposed, such as temporal fishery closures and depth restrictions for trawling, use the current policy framework and management, with appropriate incentives for the fishharvesting sector. This is an example of exploring options within the given policy framework.

In a data-rich study "Power and politics of social-ecological regime shifts in the Chilika lagoon, India and Tam Giang lagoon, Vietnam," Nayak et al. (2016) extended the concept of regime shifts to socio-ecological systems and addressed themes 1 and 2. They state that "limited attention to social dimensions restricts our ability to predict and avert impending regime shifts, or to effectively navigate where thresholds have been crossed." (Nayak et al. 2016). Having first outlined different perspectives to understanding power and politics, they use a realist view of power to explore the relationship between regime shifts and social inequities, power imbalances, and social and environmental injustices in two case studies from India and Vietnam, based on information gained through participatory field research. Power is defined as "the exercise of action and knowledge to control the allocation and/or the access to resources and further interests." They conclude that "Failure to consider social relationships of power and politics in periods of abrupt coastal and marine change will adversely affect ongoing efforts to predict and navigate changes to the benefit of ecosystems and human well-being." They also call for adaptive governance and refer to emerging ideas about "deliberative transformations." This idea is explored further in Glavovic (2016, see below).

Above we have argued that oceans are complex systems. However, some approaches are developed to try to make that complexity tractable by focusing on key processes. Selim et al. (2016) in "Direct and indirect effects of climate and fishing on changes in coastal ecosystem services: a historical perspective from the North Sea" addressed theme 2, and used partial least squares path analysis to understand the links between drivers, ecosystem processes, and the provision of fish as food in the North Sea using time series data from 1924 to 2010. The two drivers are represented by the North Atlantic Oscillation and Sea Surface Temperature (as a proxy for climate) and fishing effort (as a proxy for fishing); ecosystem processes are represented by the spawning stock biomass and recruitment of three important fish species, cod, haddock, and whiting, and the landings of these three species represent food provisions. Their results indicated that links between fishing, ecosystem processes, and food provision were strong, but that links from climate to food provision were weak. This paper joins a growing body of work using partial least squares path analysis to reduce the complexity of ecosystem processes and gain understanding to better support an ecosystem-based approach to fisheries management (e.g., Fu et al. 2015).

A thread running through all these papers, some more explicitly than others, is the role of governance. For example, Isaacs approaches her analysis through the lens of interactive governance (Kooiman et al. 2005; Chuenpagdee 2011) and Nayak et al. (2016) call for adaptive governance. In his paper "Towards deliberative coastal governance: insights from South Africa and the Mississippi Delta" and based on the lack of success of integrated coastal management, as evidenced in two case studies, Glavovic (2016) addressed theme 3 and argues that coastal management should be reconceptualized as a transformative practice of deliberative governance. Building on insights gained from a range of governance perspectives, including integrated coastal governance, risk governance, resilience, and adaptive governance, Glavovic concludes that "deliberative democracy offers a conceptually and practically robust foundation for addressing contemporary societal challenges." The tenets of deliberative democracy are that (1) it is based on communication of reason (rather than political ideology) and (2) the "choice of public policies in liberal democracies should be more democratic than prevailing pluralist politics."

As human beings we like to order things, to place things into groups that are similar to one another, and to make distinctions. Developing such classifications can also be a useful research tool, one that can help identify methods that work well, or where there are gaps in our knowledge, intuitions, or understandings. Building on the earlier work of LOICZ and the ongoing work of the IMBER Human Dimension Working Group (http://www.imber.info/Sci ence/Working-Groups/Human-Dimensions, Bundy et al. 2015), Glaeser (2016) addressed all three themes and proposed a coastal and marine socio-ecological typology in his paper "From global sustainability research matrix to typology: a tool to analyze coastal and marine socio-ecological systems." Using the socio-ecological framework, a governance baseline and the Order of Outcomes framework 
(Olsen 2009), which is also used by Glavovic (2016), Glaeser developed a two-dimensional, hierarchical typology to analyze, compare, and classify coastal and marine systems, using a case study from Indonesia as an example. He then applied his conceptual framework to nine case studies collected by the IMBER Human Dimensions Working Group. The nested typology that Glaeser developed has an explicit regional focus. It helpfully differentiates between levels and scale, and highlights the importance of a multi-level approach. In common with Bundy et al. (2015), he concludes that more case studies are required in order to develop more representative typologies.

The papers and case studies in this special collection of papers present ideas and processes that are in progress: they make it clear that David Bowie is wrong. They present examples of how to adapt to, and mitigate, the effects of global change on marine ecosystems and the human communities with which they interact. Several also suggest conceptual approaches to understand, sort, and address the issues and challenges. There are no single solutions, but a wide range of approaches that can be used to explore ideas further, to increase understanding of issues and to improve our ability to respond successfully to the impact of global change on our ocean and coastal systems. These approaches offer a variety of innovative ways in which interdisciplinary work can improve the condition of our blue planet, as well as the prospects for human communities that depend on ocean resources.

Acknowledgments AB, RC, SC, BG, and LTM were supported by IMBER to attend the IMBIZO Conference.

\section{References}

Angel DL, Edelist D, Freeman S (2016) Local perspectives on regional challenges: jellyfish proliferation and fish stock management along the Israeli Mediterranean coast Reg Environ. Change. doi:10.1007/s10113-014-0613-0

Bundy A, Chuenpagdee R, Cooley SR, Defeo O, Glaeser B, Guillotreau P, Isaacs M, Mitsutaku M, Perry RI (2015) A decision support tool for global change in marine systems. The IMBER-ADApT framework. Fish Fish. doi: 10.1111/faf.12110

Chuenpagdee R (2011) Interactive governance for marine conservation: an illustration. Bull Mar Sci 87:197-211. doi:10.5343/bms. 2010.1061

Editorial (2015) Time for the social sciences. Nature 517:4

Fu C, Large S, Knight B, Richardson AJ, Bundy A, Reygondeau G, Boldt J, Van Der Meeren GI, Torres MA, Sobrino I, Auber A, Travers-Trolet M, Piroddi C, Diallo I, Jouffre D, Mendes H, Borges MF, Lynam CP, Coll M, Shannon LJ, Shin YJ (2015) Relationships among fisheries exploitation, environmental conditions, and ecological indicators across a series of marine ecosystems. J Mar Syst 148:101-111. doi:10.1016/j.jmarsys. 2015.01 .004

Glaeser B (2016) From global sustainability research matrix to typology: a tool to analyze coastal and marine social-ecological systems. Reg Environ Change. doi:10.1007/s10113-015-0817-y

Glavovic BC (2016) Towards deliberative coastal governance: insights from South Africa and the Mississippi Delta. Reg Environ Change. doi:10.1007/s10113-014-0727-4

Harnik PG, Lotze HK, Anderson SC, Finkel ZV, Finnegan S, Lindberg DR, Tittensor DP (2012) Extinctions in ancient and modern seas. TREE 27(11):608-617. doi:10.1016/j.tree.2012.07. 010

Isaacs M (2016) Multi-stakeholder process of co-designing smallscale fisheries policy in South Africa. Reg Env Change. doi:10. 1007/s10113-015-0874-2

Jackson JB, Kirby MX, Berger WH, Bjorndal KA, Botsford LW, Bourque BJ, Bradbury RH, Cooke R, Erlandson J, Estes JA, Hughes TP, Kidwell S, Lange CB, Lenihan HS, Pandolfi JM, Peterson CH, Steneck RS, Tegner MJ, Warner RR (2001) Historical overfishing and the recent collapse of coastal ecosystems. Science 293(5530):629-637

Kittinger JN, Bambico TM, Minton D, Miller A, Mejia M, Kalei N, Glazier EW (2016) Restoring ecosystems restoring community: socioeconomic and cultural dimensions of a community-based coral reef restoration project. Reg Environ Change. doi:10.1007/ s10113-013-0572-x

Kooiman J, Bavinck M, Jentoft S, Pullin R (eds) (2005) Fish for life: interactive governance for fisheries. Amsterdam University Press, Amsterdam

Lotze HK, Lenihan HS, Bourque BJ, Bradbury RH, Cooke RG, Kay MC, Kidwell SM, Kirby MX, Peterson CH, Jackson JB (2006) Depletion degradation and recovery potential of estuaries and coastal seas. Science 312(5781):1806-1809. doi:10.1126/ science. 1128035

Lövbrand E, Beck S, Chilvers J, Forsyth T, Hedrén J, Hulme M, Vasileiadou E (2015) Who speaks for the future of Earth? How critical social science can extend the conversation on the Anthropocene. Glob Environ Change 32:211-218. doi:10.1016/ j.gloenvcha.2015.03.012

Munas M, Lokuge G (2016) Shocks and coping strategies of coastal communities in war-conflict-affected areas of the north and east of Sri Lanka. Reg Environ Change. doi:10.1007/s10113-0140632-x

Nayak PK, Armitage D, Andrachuk M (2016) Power and politics of social-ecological regime shifts in the Chilika lagoon India and Tam Giang lagoon Vietnam. Reg Environ Change. doi:10.1007/ s10113-015-0775-4

Olsen SB, Page GG, Ochoa E (2009) The analysis of governance responses to ecosystem change. A handbook for assembling a baseline. LOICZ Reports and Studies No. 34. GKSS Research Center, Geesthacht (Germany)

Pohl C (2011) What is progress in transdisciplinary research? Futures 43:618-626

Scheffer M, Carpenter S, Foley JA, Folke C, Walker B (2001) Catastrophic shifts in ecosystems. Nature 413(6856):591-596. doi: $10.1038 / 35098000$

Selim SA, Blanchard JL, Bedford J, Webb TJ (2016) Direct and indirect effects of climate and fishing on changes in coastal ecosystem services: a historical perspective from the North Sea. Reg Environ Change. doi:10.1007/s10113-014-0635-7

Victor DG (2015) Embed the social sciences in climate policy. Nature 520:27-29 